\title{
Breast-feeding and postpartum maternal weight trajectories
}

\author{
Laura Mullaney ${ }^{1, *}$, Amy C O'Higgins², Shona Cawley', Rachel Kennedy', \\ Daniel McCartney ${ }^{1}$ and Michael J Turner ${ }^{2}$ \\ ${ }^{1}$ School of Biological Sciences, Dublin Institute of Technology, Dublin 8, Republic of Ireland: ${ }^{2}$ UCD Centre \\ for Human Reproduction, Coombe Women and Infants University Hospital, Dublin, Republic of Ireland
}

Submitted 24 April 2015: Final revision received 21 August 2015: Accepted 15 September 2015: First published online 15 0ctober 2015

\begin{abstract}
Objective: We examined whether breast-feeding, and in particular exclusive breast-feeding, was associated with maternal weight and body composition changes at 4 months postpartum independently of other maternal variables.

Design: Prospective longitudinal study. Women were recruited in the first trimester after an ultrasound examination confirmed an ongoing singleton pregnancy. Weight and body composition were measured using advanced bio-electrical impedance analysis at the first antenatal visit and 4 months postpartum. Detailed questionnaires were completed on breast-feeding, socio-economic status, diet and exercise in addition to routine clinical and sociodemographic details.

Setting: Large Irish university maternity hospital.

Subjects: Women who delivered a baby weighing $\geq 500 \mathrm{~g}$ between November 2012 and March 2014.

Results: At the postpartum visit, the mean weight was 70.9 (SD 14.2$) \mathrm{kg}(n$ 470) and the mean BMI was 25.9 (SD 5.0 ) $\mathrm{kg} / \mathrm{m}^{2}$. 'Any breast-feeding' was reported by $65 \cdot 1 \%$ of women $(n 306)$. Irish nativity $(\mathrm{OR}=0.085, P<0 \cdot 001)$, current smoking (OR=0.385, $P=0.01)$, relative income poverty $(\mathrm{OR}=0.421, P=0.04)$ and deprivation ( $\mathrm{OR}=0.458, P=0.02)$ were negatively associated with exclusive breast-feeding. At 4 months postpartum there was no difference in maternal weight change between women who exclusively breast-fed and those who formula-fed $(+2 \cdot 0 \quad v \cdot+1 \cdot 1 \mathrm{~kg}, P=0 \cdot 13)$. Women who exclusively breast-fed had a greater increase in percentage body fat at 4 months postpartum compared with women who formula-fed $(+1.0 v .-0.03 \%, P=0.02)$, even though their dietary quality was better. Exclusive breast-feeding was not associated with postpartum maternal weight or body fat percentage change after adjusting for other maternal variables.

Conclusions: There are many reasons why breast-feeding should be strongly promoted but we found no evidence to support postpartum weight management as an advantage of breast-feeding.
\end{abstract}

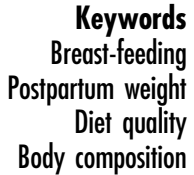

The benefits of breast-feeding for mother and child are well established ${ }^{(1,2)}$. Variables associated with breastfeeding rates include socio-economic status, education, smoking, maternal age and pre-pregnancy weight ${ }^{(3-6)}$. The postpartum period has been associated with an increase in food intake and a decrease in physical activity level $(\mathrm{PAL})^{(7-9)}$. Breast-feeding also has been shown to be positively associated with improved dietary quality in overweight and obese women ${ }^{(10,11)}$. However, no differences in PAL have been observed between women who never initiated breast-feeding and those who practise exclusive breast-feeding $(\mathrm{EBF})^{(12)}$.

The influence of breast-feeding on postpartum weight changes is not clear. Some studies suggest that breast-feeding aids postpartum weight loss while others challenge that belief ${ }^{(13)}$. EBF has been associated with greater weight loss; however, this relationship is not consistent between studies ${ }^{(13)}$. Longitudinal studies that investigate breast-feeding and postpartum weight changes usually rely on self-reporting of maternal pre-pregnancy weight, which has limitations ${ }^{(13,14)}$. Self-reporting of weight in obese women may be particularly subject to error $^{(15)}$. There is a lack of longitudinal studies in which both maternal pre-pregnancy and postpartum weights are measured and weight changes analysed by infant feeding practices. Further studies are also needed to ascertain whether some breast-feeding women lose weight postpartum more readily than others. 
Conflicting results have also been found with regard to breast-feeding and its effect on maternal body composition. The majority of studies report little or no association between breast-feeding and body composition. However, many of these studies rely on small sample sizes ${ }^{(13)}$. There is a paucity of research investigating the association between breast-feeding and other maternal variables that can be examined independently of dietary quality and physical activity.

The purpose of the present paper was to examine whether breast-feeding, and in particular EBF, was associated with maternal weight and body composition changes after delivery independently of other variables such as diet, physical activity, smoking, socio-economic disadvantage and demographic differences.

\section{Methods}

The Coombe Women and Infants University Hospital is one of the largest maternity hospitals in the European Union and cares for women from all socio-economic groups and from across the urban-rural divide. Women were recruited at their convenience after an ultrasound examination confirmed an ongoing singleton pregnancy.

Clinical and sociodemographic details were computerised routinely at the first visit and after delivery. In addition, socio-economic, health behavioural and PAL data were collected at the first visit using standardised questionnaires. Height was measured to the nearest centimetre using a Seca wall-mounted digital height measure with the woman standing in her bare feet. Weight and body composition were measured using advanced, eightelectrode bio-electrical impedance analysis (Tanita MC 180, Tokyo, Japan) and BMI was calculated. Women received no lifestyle interventions as part of the research during or after pregnancy other than the standard antenatal care.

Women were invited back to the hospital for review at 4 months postpartum. Socio-economic, health behavioural and PAL data were again gathered at this visit, and the woman's weight, body composition and BMI re-measured. The women's dietary quality information was also gathered. The study was approved by the Hospital's Research Ethics Committee on 16 May 2012. Written informed consent was obtained from each participant.

\section{Inclusion/exclusion criteria}

The main inclusion criteria were attendance for antenatal care following ultrasound examination and confirmation of an ongoing singleton pregnancy in the first trimester. To reduce the number of confounding variables, the main exclusion criteria were multiple pregnancy, women $<18$ years of age and women with a gestational age $>18$ weeks at the first booking visit. Women who delivered elsewhere were also excluded.

\section{Health behavioural information and socio-economic status}

The health behavioural information gathered included any medical conditions, medications, smoking status and PAL. Additional questions collecting socio-economic data were derived from the Survey on Income and Living Conditions $2012^{(16)}$. Material indices of socio-economic status included relative income poverty and relative deprivation status, while consistent poverty status was also calculated $^{(17)}$. Relative income poverty was calculated by comparing equivalised household income against the $60 \%$ median income threshold. Relative deprivation was assessed by determining whether respondents had experienced the enforced absence (due to financial constraint) of two or more basic necessities from a list of eleven over the previous year. Consistent poverty was identified if a respondent's equivalised household income fell below the relative income poverty threshold, in addition to experiencing the enforced absence of two or more of the eleven basic markers of deprivation over the previous year ${ }^{(17)}$.

Self-assessed habitual PAL was also collected using a self-administered, unsupervised questionnaire. Individual PAL was estimated for each participant from 1.45 MET (seated work with no option of moving around and no strenuous leisure-time activity) up to 2.20 MET (strenuous work or highly active leisure-time activity, e.g. competitive athletes in daily training ${ }^{(18)}$, where MET is metabolic equivalents of task.

\section{Dietary quality data}

Dietary quality data were collected using a selfadministered, unsupervised questionnaire. This included information about the respondent's meal pattern (number of meals per day) and her habitual intakes of fruit and vegetables, breakfast cereals and oily fish. Participants' starchy food, meat and poultry, dairy food and sugary food and drink intakes were also recorded. Intakes of fatrich foods including chips and savoury snacks were determined next, with participants finally asked to estimate their habitual alcohol intake and their daily intakes of water and other sugar-free fluids.

Each of the dietary domains was ranked, based on its respective nutritional importance in pregnancy. For example, breakfast cereals were highlighted as a priority food group due to their high content of critical nutrients for pregnancy including folate, Fe and vitamin $\mathrm{D}^{(19-21)}$. Dietary domain scores were derived for each domain based on the participant's consumption of foods within that domain, and these scores were amalgamated to yield one composite score reflecting the overall quality of the participant's diet (range of 0 to 100).

\section{Infant feeding practices}

When they returned for their 4-month postpartum visit women were asked by questionnaire whether they had breast-fed after delivery. Breast-feeding women were 
also asked at this postpartum visit whether they had exclusively breast-fed (EBF; only breast milk, no formula) or engaged in partial breast-feeding (breast milk and formula combined). Women were asked how long they had breast-fed for, with options ranging from '0 to 3 days', ' 4 to 6 days', ' 1 week' with weekly options up to ' 12 weeks', '3 months' with monthly options to ' 5 months' to finally whether they were 'still breastfeeding'.

To capture both the intensity and duration of breastfeeding we used a scale that reflects the energy costs of full and partial breast-feeding ${ }^{(22,23)}$. Women were assigned 1 point/week for EBF and 0.5 point/week for partial breast-feeding. The breast-feeding scale was used as a continuous scale.

\section{Statistical analysis}

Data analysis was carried out using the statistical software package IBM SPSS Statistics version 20.0. Baseline anthropometric characteristics of the women who returned for follow-up were compared with those of the total original sample using independent-samples $t$ tests, to ensure that the final prospective cohort was representative of the broader study population. Age and anthropometric characteristics of the exclusive breast-feeders were compared with those of women who formula-fed using independent-samples $t$ tests. Cross-tabulation with $\chi^{2}$ analyses were used to test differences between the proportions of exclusive breast-feeders and women who formula-fed in different socio-economic and health behavioural groups.

Binary logistic regression was performed to assess the unconfounded association between a number of factors and participants' self-reported EBF and formula-feeding practices. The final model comprised seven independent variables (nativity, obesity, relative income poverty, relative deprivation, consistent poverty, nulliparity and current smoking status). Factors were included in the multivariate model based on a statistically significant association with infant feeding method upon univariate analyses $(P<0 \cdot 05)$.

Differences in maternal body weight and body composition changes between baseline and 4 months postpartum between women who EBF and women who formula-fed were analysed by the Mann-Whitney $U$ test as these data were non-normally distributed. Differences in PAL and dietary quality at 4 months postpartum were analysed according to infant feeding practices using the KruskalWallis test.

Binary logistic regression was performed to assess the association between a number of factors and maternal weight and body fat percentage gain or loss postpartum. The model contained eight independent variables (early pregnancy obesity status, nulliparity, stage of gestation at booking visit, birth weight, dietary quality score, breastfeeding scale, PAL and EBF).

\section{Results}

The total sample recruited initially in the first trimester was 1035 women and $98 \%$ ( $n$ 1018) delivered a live-born baby in the Hospital between November 2012 and March 2014. At 4 months postpartum, 470 women agreed to return for repeat measurements for research purposes and completed the breast-feeding questionnaire. Women who returned for follow-up ( $n$ 470) did not differ from the full baseline sample ( $n$ 1035) in weight, BMI or stage of gestation at booking visit. Women who did not return were younger (28.9 v. 30.9 years, $P=0 \cdot 001)$ and more likely to be current smokers (20.2 v. $9.7 \%, P=0.001)$ than women who returned.

The mean stage of gestation at booking ( $n$ 470) was $12 \cdot 4$ (SD 1.7) weeks and mean postpartum follow-up was at 18.0 (SD 2.2) weeks. The mean age at recruitment was 30.8 (SD 5.0) years. The mean antenatal weight was 69.2 (SD 14.2) $\mathrm{kg}$ and mean antenatal BMI was $25.3(\mathrm{sD} 5 \cdot 1) \mathrm{kg} / \mathrm{m}^{2}$, with $14.9 \%$ of participants ( $n$ 70) obese. Forty-three per cent ( $n$ 213) of the women were nulliparous. The women's mean dietary quality score was 68.3 (SD 26.0). Women who EBF had a mean breast-feeding scale score of 11.8 (SD 5.2) and women who partially breast-fed a breast-feeding scale score of $4 \cdot 1$ (sD 3·1).

The mean postpartum weight was 70.9 ( $\mathrm{sD} 14.2) \mathrm{kg}$ and the mean BMI was 25.9 (SD 5.0) $\mathrm{kg} / \mathrm{m}^{2}$. The characteristics of the study population analysed by postpartum infant feeding method are shown in Table 1. Women who EBF reported breast-feeding for $86 \cdot 0$ (sD 46.6) d (range 1.5-168d), whereas women who partially breast-fed reported breast-feeding for 56.8 (sD 43.5) d (range 1.5-168d; $P<0 \cdot 001$ ). When binary logistic regression was performed to assess the association between a number of maternal factors and the likelihood that women would EBF or not breast-feed, relative income poverty $(P=0.04)$, deprivation $(P=0.02)$, Irish nativity $(P<0.001)$ and current tobacco use $(P=0 \cdot 01)$ remained negatively associated with EBF (Table 2).

There was no difference in maternal weight change from baseline to 4 months postpartum between women who EBF and those who did not breast-feed (Table 3). Women who EBF, however, had an increased fat mass $(P=0.03)$ and percentage body fat $(P=0.02)$ between early pregnancy and 4 months postpartum compared with non-breast-feeders. We found no relationship between infant feeding and postpartum changes in fat distribution (Table 4). Women who EBF had a better dietary quality score than women who did not breast-feed or those who partially breast-fed $(P<0 \cdot 001)$. There was no relationship between PAL and infant feeding practices (Table 5).

After controlling for breast-feeding, breast-feeding scale, nulliparity, stage of gestation at booking and PAL, only 
Table 1 Characteristics of the study population at 4 months postpartum analysed by postpartum infant feeding method ( $n$ 470), Dublin, Republic of Ireland

\begin{tabular}{|c|c|c|c|c|c|c|c|}
\hline & \multicolumn{2}{|c|}{ Formula-feeding ( $n$ 164) } & \multicolumn{2}{|c|}{ Partial breast-feeding ( $n$ 114) } & \multicolumn{2}{|c|}{ Exclusive breast-feeding ( $n$ 192) } & \multirow[b]{2}{*}{$P$ value* } \\
\hline & Mean & SD & Mean & SD & Mean & SD & \\
\hline Age (years) & 30.5 & $5 \cdot 6$ & $32 \cdot 9$ & 4.6 & $31 \cdot 7$ & 4.4 & NS \\
\hline Weight $(\mathrm{kg})$ & $72 \cdot 2$ & $15 \cdot 5$ & $70 \cdot 9$ & 14.6 & $70 \cdot 1$ & $12 \cdot 6$ & NS \\
\hline \multirow[t]{2}{*}{ BMI $\left(\mathrm{kg} / \mathrm{m}^{2}\right)$} & $26 \cdot 4$ & $5 \cdot 6$ & $25 \cdot 9$ & $5 \cdot 1$ & $25 \cdot 4$ & 4.4 & $<0.05$ \\
\hline & \multicolumn{2}{|c|}{$\%$} & \multicolumn{2}{|c|}{$\%$} & \multicolumn{2}{|c|}{$\%$} & \\
\hline Obese & \multicolumn{2}{|c|}{$25 \cdot 0$} & \multicolumn{2}{|c|}{17.5} & \multicolumn{2}{|c|}{$15 \cdot 1$} & 0.01 \\
\hline Nulliparous & \multicolumn{2}{|c|}{34.8} & \multicolumn{2}{|c|}{53.5} & \multicolumn{2}{|c|}{43.8} & 0.03 \\
\hline Irish nativity & \multirow{2}{*}{\multicolumn{2}{|c|}{94.5}} & \multicolumn{2}{|c|}{63.2} & \multicolumn{2}{|c|}{$60 \cdot 4$} & 0.002 \\
\hline Currently smoking & & & \multicolumn{2}{|c|}{$10 \cdot 5$} & \multicolumn{2}{|c|}{9.9} & $<0.001$ \\
\hline Caesarean section & \multicolumn{2}{|c|}{$\begin{array}{l}2<\cdot 0 \\
17 \cdot 7\end{array}$} & \multirow{2}{*}{\multicolumn{2}{|c|}{$\begin{array}{r}24.6 \\
6.2\end{array}$}} & \multicolumn{2}{|c|}{$20 \cdot 3$} & NS \\
\hline Risk of povertyt & \multicolumn{2}{|c|}{23.8} & & & \multicolumn{2}{|c|}{11.5} & 0.002 \\
\hline Relative deprivation & \multicolumn{2}{|c|}{29.3} & \multicolumn{2}{|c|}{18.4} & & & 0.002 \\
\hline \multirow[t]{2}{*}{ Consistent poverty } & \multicolumn{2}{|c|}{$10 \cdot 4$} & \multicolumn{2}{|c|}{3.5} & \multicolumn{2}{|c|}{$2 \cdot 6$} & 0.002 \\
\hline & Mean & SD & Mean & SD & Mean & SD & \\
\hline Any breast-feeding duration (d) & 0 & - & $56 \cdot 8$ & 43.5 & $86 \cdot 0$ & $46 \cdot 6$ & $<0.001$ \\
\hline
\end{tabular}

* $P$ value testing for significant difference between formula-feeding and exclusive breast-feeding (except for 'Any breast-feeding duration' variable, where $P$ value tests for significant difference between partial breast-feeding and exclusive breast-feeding) using independent-samples $t$ tests and $\chi^{2}$ analyses. †Data available on $n 469$.

Table 2 Binary logistic regression of postpartum factors associated with exclusive breast-feeding compared with formula-feeding ( $n$ 356), Dublin, Republic of Ireland

\begin{tabular}{|c|c|c|c|c|}
\hline & $n$ & OR & $95 \% \mathrm{Cl}$ & $P$ value \\
\hline \multicolumn{5}{|l|}{ Nativity } \\
\hline Non-Irish & 85 & 1.0 & Ref. & \\
\hline Irish-born & 271 & 0.085 & $0.04,0.2$ & $<0.001$ \\
\hline \multicolumn{5}{|l|}{ Obesity } \\
\hline Obese & 70 & 1.0 & Ref. & \\
\hline Non-obese & 286 & 1.523 & $0.9,2.9$ & NS \\
\hline \multicolumn{5}{|c|}{ Relative income poverty } \\
\hline Yes & 61 & 0.421 & $0.2,1.0$ & 0.04 \\
\hline No & 295 & 1.0 & Ref. & \\
\hline \multicolumn{5}{|c|}{ Relative deprivation } \\
\hline Yes & 73 & 0.458 & $0.2,0.9$ & 0.02 \\
\hline No & 283 & 1.0 & Ref. & \\
\hline \multicolumn{5}{|c|}{ Consistent poverty } \\
\hline Yes & 22 & 1.715 & $0.4,7.6$ & NS \\
\hline No & 334 & 1.0 & Ref. & \\
\hline \multicolumn{5}{|l|}{ Nulliparous } \\
\hline No & 214 & 1.0 & Ref. & \\
\hline Yes & 142 & 1.225 & $0.8,2.0$ & NS \\
\hline \multicolumn{5}{|c|}{ Smoking currently } \\
\hline Former/never & 299 & 1.0 & Ref. & \\
\hline Current & 57 & 0.385 & $0.2,0.8$ & 0.01 \\
\hline
\end{tabular}

Table 3 Differences in maternal weight and body composition changes between early pregnancy and 4 months postpartum according to infant feeding practices ( $n$ 470), Dublin, Republic of Ireland

\begin{tabular}{|c|c|c|c|c|c|c|c|}
\hline & \multicolumn{2}{|c|}{ Formula-feeding ( $n$ 164) } & \multicolumn{2}{|c|}{ Partial breast-feeding $(n 114)$} & \multicolumn{2}{|c|}{ Exclusive breast-feeding ( $n$ 192) } & \multirow[b]{2}{*}{$P$ value* } \\
\hline & Mean & Range & Mean & Range & Mean & Range & \\
\hline Weight $(\mathrm{kg})$ & $+1 \cdot 1$ & $-18 \cdot 8$ to $17 \cdot 8$ & $+1 \cdot 7$ & -7.6 to 10.2 & $+2 \cdot 0$ & $-8 \cdot 2$ to 17.9 & NS \\
\hline Fat mass $(\mathrm{kg})$ & +0.4 & -14.8 to 13.3 & +0.8 & -9.1 to 9.2 & $+1 \cdot 2$ & -6.3 to 10.8 & 0.03 \\
\hline Fat mass $(\%)$ & -0.03 & -9.8 to 9.1 & +0.4 & -8.5 to 8.7 & $+1 \cdot 0$ & -11.0 to 12.4 & 0.02 \\
\hline Fat-free mass (kg) & +0.7 & -7.2 to 7.0 & +0.9 & -4.5 to 6.0 & +0.7 & -4.9 to 11.3 & NS \\
\hline Total body water $(\mathrm{kg})$ & +0.5 & -5.0 to 5.0 & +0.6 & -3.2 to 4.2 & +0.6 & -3.5 to 8.0 & NS \\
\hline Bone mass $(\mathrm{kg})$ & +0.04 & -0.3 to 0.3 & +0.04 & -0.2 to 0.3 & +0.04 & -0.3 to 0.6 & NS \\
\hline Visceral fat level & $+0 \cdot 2$ & -4.0 to 3.0 & +0.3 & $-2 \cdot 0$ to $2 \cdot 0$ & +0.3 & -2.0 to 3.0 & NS \\
\hline
\end{tabular}

${ }^{\star} P$ value testing for significant difference between formula-feeding and exclusive breast-feeding using Mann-Whitney $U$ test. 
Table 4 Difference in maternal segmental body composition changes between early pregnancy and 4 months postpartum according to infant feeding practices ( $n$ 467), Dublin, Republic of Ireland

\begin{tabular}{|c|c|c|c|c|c|c|c|}
\hline & \multicolumn{2}{|c|}{ Formula-feeding ( $n$ 167) } & \multicolumn{2}{|c|}{ Partial breast-feeding ( $n$ 114) } & \multicolumn{2}{|c|}{ Exclusive breast-feeding ( $n$ 186) } & \multirow[b]{2}{*}{$P$ value ${ }^{\star}$} \\
\hline & Mean & Range & Mean & Range & Mean & Range & \\
\hline Right arm fat (kg) & +0.001 & -1.0 to 0.8 & +0.02 & -0.5 to 0.7 & +0.05 & -0.5 to 0.8 & NS \\
\hline Right arm fat (\%) & -1.02 & -12.8 to 9.9 & $-1 \cdot 1$ & -12.6 to 8.3 & -0.2 & -14.0 to 17.3 & NS \\
\hline Left arm fat $(\mathrm{kg})$ & -0.01 & -1.2 to 1.0 & +0.01 & -0.4 to 0.7 & +0.04 & -0.7 to 1.0 & NS \\
\hline Left arm fat (\%) & $-1 \cdot 3$ & -12.5 to 10.4 & -1.2 & -12.6 to 10.6 & -0.5 & -16.1 to 11.6 & NS \\
\hline Right leg fat $(\mathrm{kg})$ & +0.2 & -3.6 to 4.1 & +0.4 & -3.5 to 3.5 & +0.3 & -2.3 to 5.0 & NS \\
\hline Right leg fat (\%) & +1.3 & -18.8 to 33.0 & +2.5 & -23.2 to 31.4 & +1.9 & -20.1 to 37.9 & NS \\
\hline Left leg fat $(\mathrm{kg})$ & +0.2 & -5.7 to 3.0 & +0.3 & -2.8 to 3.1 & +0.4 & -2.3 to 3.8 & NS \\
\hline Left leg fat $(\%)$ & +1.0 & -31.6 to 26.5 & $+1 \cdot 7$ & -18.7 to 25.1 & $+2 \cdot 0$ & -17.4 to 29.0 & NS \\
\hline Trunk fat $(\mathrm{kg})$ & -0.01 & -5.4 to 7.4 & +0.005 & -4.8 to 5.2 & +0.3 & -5.4 to 5.7 & NS \\
\hline Trunk fat $(\%)$ & -0.6 & -10.9 to 13.9 & -0.8 & -14.4 to 8.7 & +0.1 & -17.0 to 14.7 & NS \\
\hline
\end{tabular}

${ }^{*} P$ value testing for significant difference between formula-feeding and exclusive breast-feeding using Mann-Whitney $U$ test.

Table 5 Dietary quality scores and physical activity levels according to infant feeding practices ( $n$ 450), Dublin, Republic of Ireland

\begin{tabular}{|c|c|c|c|c|c|c|c|}
\hline & \multicolumn{2}{|c|}{ Formula-feeding ( $n$ 157) } & \multicolumn{2}{|c|}{ Partial breast-feeding ( $n$ 109) } & \multicolumn{2}{|c|}{ Exclusive breast-feeding ( $n$ 184) } & \multirow[b]{2}{*}{$P$ value* } \\
\hline & Mean & SD & Mean & SD & Mean & SD & \\
\hline Dietary quality score & 60.5 & $25 \cdot 4$ & 68.1 & $26 \cdot 9$ & $75 \cdot 4$ & $24 \cdot 0$ & $<0.001$ \\
\hline Physical activity (MET) & 1.79 & 0.2 & 1.78 & 0.13 & 1.76 & 0.20 & NS \\
\hline
\end{tabular}

MET, metabolic equivalents of task.

${ }^{*} P$ value tested using Kruskal-Wallis test.

Table 6 Logistic regression of factors associated with maternal weight and body fat percentage gain at 4 months postpartum $(n 337$ for whom all variables were available), Dublin, Republic of Ireland

\begin{tabular}{|c|c|c|c|c|c|c|c|}
\hline & \multirow[b]{2}{*}{$n$} & \multicolumn{3}{|c|}{ Weight gain } & \multicolumn{3}{|c|}{ Body fat percentage gain } \\
\hline & & OR & $95 \% \mathrm{Cl}$ & $P$ value & OR & $95 \% \mathrm{Cl}$ & $P$ value \\
\hline \multicolumn{8}{|l|}{ Antenatal obesity } \\
\hline Obese & 52 & 1.0 & Ref. & & 1.0 & Ref. & \\
\hline Non-obese & 285 & 3.778 & $2 \cdot 0,7 \cdot 2$ & $<0.001$ & 2.729 & $1 \cdot 4,5 \cdot 3$ & 0.003 \\
\hline \multicolumn{8}{|c|}{ Physical activity level } \\
\hline Linear variable & 337 & 3.679 & $0 \cdot 8,17 \cdot 4$ & NS & 1.747 & $0.4,7.4$ & NS \\
\hline \multicolumn{8}{|c|}{ Exclusive breast-feeding } \\
\hline No & 156 & 1.0 & Ref. & & $1 \cdot 0$ & Ref. & \\
\hline Yes & 181 & 0.901 & $0.4,2.2$ & NS & 0.752 & $0.3,1.7$ & NS \\
\hline \multicolumn{8}{|c|}{ Breast-feeding scale } \\
\hline Linear variable & 337 & 1.015 & $1 \cdot 0,1 \cdot 1$ & NS & 1.047 & $1 \cdot 0,1 \cdot 1$ & NS \\
\hline \multicolumn{8}{|l|}{ Booking gestation } \\
\hline Linear variable & 337 & 0.955 & $0 \cdot 8,1 \cdot 1$ & NS & 0.939 & $0 \cdot 8,1 \cdot 1$ & NS \\
\hline \multicolumn{8}{|l|}{ Dietary quality } \\
\hline Linear variable & 337 & 1.011 & $1 \cdot 0,1 \cdot 1$ & 0.03 & 1.011 & $1 \cdot 0,1 \cdot 1$ & 0.02 \\
\hline \multicolumn{8}{|l|}{ Birth weight } \\
\hline Linear variable & 337 & 0.944 & $0.6,1.5$ & NS & 1.085 & $0 \cdot 7,1 \cdot 7$ & NS \\
\hline \multicolumn{8}{|l|}{ Nulliparous } \\
\hline No & 203 & & Ref. & & $1 \cdot 0$ & Ref. & \\
\hline Yes & 134 & $1 \cdot 311$ & $0.8,2 \cdot 2$ & NS & 1.059 & $0 \cdot 7,1 \cdot 7$ & NS \\
\hline
\end{tabular}

Ref., reference category.

early pregnancy $\mathrm{BMI}<30 \cdot 0 \mathrm{~kg} / \mathrm{m}^{2}$ and diet quality score remained associated with weight and body fat percentage gain at 4 months postpartum (Table 6).

\section{Discussion}

We found in a longitudinal observational study that on univariate analysis obese women were less likely to breast-feed, but that EBF was associated with an increase on average in maternal weight and an increase in maternal adiposity. Women who breast-fed were more likely to put on weight and to become fatter even though their diet quality was superior and their PAL was similar to women who formula-fed. They were also less likely to smoke, less likely to be socially deprived and less likely to have been born in Ireland. EBF was not associated with postpartum maternal weight or body fat percentage changes after 
adjusting for maternal obesity, breast-feeding duration, PAL, booking gestation, dietary quality, infant birth weight and nulliparity. Therefore, we found no evidence to support promoting breast-feeding on the basis of improving maternal weight postpartum. As part of a public health strategy to promote breast-feeding there are more convincing reasons why a woman should breast-feed exclusively $^{(1,2)}$.

Our study has strengths. The study population is well characterised. The clinical and sociodemographic details were computerised as usual at the first antenatal visit and after delivery, but additional data were collected prospectively using detailed questionnaires that gathered information on breast-feeding, dietary quality, physical activity and social disadvantage.

A further strength of our study was the clinical measurement (rather than self-reporting) of early pregnancy weight. The baseline weight measurement and BMI calculations were obtained before 18 weeks' gestation, which is optimal ${ }^{(24)}$. There are few studies investigating measured differences in weight and BMI between early pregnancy and the postpartum period, with many studies relying on self-reported pre-pregnancy weight which is unreliable and leads to BMI misclassification ${ }^{(14)}$. Self-reporting of weight in obese women may be particularly subject to error ${ }^{(15)}$. To our knowledge, the present study is one of the largest to measure maternal body composition directly using advanced bio-electrical impedance analysis, which means that trajectories in fat and fat-free mass can be tracked over time and analysed by infant feeding practices.

Another strength of the study is that its prospective design minimises recall bias which is a potential problem with post-pregnancy research ${ }^{(25)}$. The study also highlights the advantage of longitudinal studies. Based on a cross-sectional analysis postpartum maternal obesity was associated with formula-feeding; however, on longitudinal analysis maternal weight gain was associated with breastfeeding. Our longitudinal study design overcomes this critical inability of cross-sectional studies to measure changes in anthropometric status between the antenatal and postpartum time points.

A potential weakness of the study is that recall bias may have occurred at 4 months postpartum when women reported their breast-feeding duration. Women were asked how long they had breast-fed. While the inability of this question to differentiate between EBF and partial breast-feeding introduces a degree of imprecision, this limitation is mitigated by the use of a scale that captures the intensity and duration of breast-feeding (and hence estimates the overall bio-energetic cost of breast-feeding during the postpartum period) for both EBF and partial breast-feeding mothers. Another potential weakness of the study is that convenience recruitment may introduce an unforeseen bias that was not addressed in the multivariable analysis. However, consecutive recruitment is practically challenging in a longitudinal study whose timeframe spans early pregnancy until four months following a woman's discharge home with her newborn baby. We are also uncertain whether our observations are applicable in the developing world.

The benefits of breast-feeding for mother and child are well established ${ }^{(1,2)}$. Many factors have been associated with breast-feeding rates including nationality, socioeconomic status, education, smoking status, maternal age and pre-pregnancy weight ${ }^{(3-6)}$. In the present study, multivariate analysis showed that women who smoked, who were Irish and who were living in relative income poverty and deprivation were less likely to EBF.

It has been suggested that common lifestyle risk factors cluster among adults ${ }^{(26)}$. In this context, our study suggests a clustering of poorer health behaviours among women who choose to formula-feed. This suggestion is further strengthened by our finding that women who EBF had better dietary quality scores than women who partially breast-fed or formula-fed. Insight into the prevalence of clustering is important, because it can potentially help in locating high-risk groups where multi-component health promotion initiatives may yield extra benefit ${ }^{(26)}$. Our study findings have public health implications as they show that additional emphasis on breast-feeding promotion may be needed in women of low socio-economic status who have other adverse health behaviours such as smoking.

There is insufficient evidence to assert a benefit for breast-feeding in postpartum weight loss ${ }^{(13)}$, yet this remains a commonly held belief ${ }^{(2,4,27)}$. Many studies in this area rely on self-reporting of maternal weight, which has limitations ${ }^{(14)}$. Consequently, it has been suggested that more robust studies are needed to reliably assess the impact of breast-feeding on postpartum weight management ${ }^{(13)}$. In our study, there was no difference in weight change from early pregnancy to 4 months postpartum between women who EBF and those who formula-fed. The perception that breast-feeding aids postpartum weight loss may, therefore, not be true for all women. Overweight and obese women with persistently high, unrealistic expectations of breast-feeding and weight loss have been shown to give up on breast-feeding earlier ${ }^{(4)}$. For this reason, evidence-based breast-feeding promotion strategies may need to focus on health benefits to the mother and child other than weight loss.

In our study, women who EBF had a greater increase in postpartum fat mass and percentage body fat compared with women who formula-fed. Conflicting results have also been found in relation to breast-feeding and its effect on maternal body composition, with the majority of studies reporting little or no association between breast-feeding and body composition. However, many of these studies rely on small sample sizes ${ }^{(13)}$. When dual-energy X-ray absorptiometry was used to measure body composition in a US study ( $n$ 168), non-breast-feeding women lost wholebody, arm and leg fat at a faster rate than the breast-feeding 
women (who intended to breast-fed for $>6$ months and to provide no more than one formula feeding per day) between 2 weeks and 6 months postpartum ${ }^{(28)}$.

It has been reported that body fat deposition during lactation occurs at central sites, for example, on the trunk and thighs ${ }^{(29)}$. Although no difference in body fat distribution between lactating and non-lactating women was observed in our study, it may be that lactating women have an overall physiological increase in body fat to support the extra energy costs of lactation. Further longitudinal studies are needed to clarify whether postpartum changes in fat distribution are influenced by breast-feeding.

\section{Conclusions}

The present study found that exclusive breast-feeding was not associated with postpartum maternal weight or body fat percentage changes after adjusting for important confounders. Breast-feeding promotion strategies may need to focus on women of low socio-economic status. These women, who may be subject to a clustering of poor lifestyle behaviours, such as smoking and poorer dietary quality, may benefit from the established advantages to mother and child of breast-feeding. The perception that breast-feeding aids postpartum weight loss, however, is not true for all women. Clinicians should be cautious when advising mothers about expected rates of weight and fat loss during lactation. Breast-feeding promotion strategies should instead focus on health benefits to mother and child other than maternal weight loss.

\section{Acknowledgements}

Acknowledgements: The authors acknowledge with gratitude the participation of the pregnant women who took part in this study. Financial support: This project was supported by the UCD Centre for Human Reproduction and was partially funded by an unlimited educational grant from Danone Nutricia Early Life Nutrition for the first author. Danone Nutricia Early Life Nutrition had no role in the study design, data analysis, data interpretation or writing of this article. Conflict of interest: The authors declare no conflict of interests. Authorship: All authors contributed to this work. L.M., A.C.O.H., D.Mc.C. and M.T.J. formulated the research question and developed the experimental design. L.M., A.C.O.H., S.C. and R.K. collected the data. L.M. analysed the data. All authors contributed to drafting and revisions of the manuscript and approved the final version prior to submission. Ethics of human subject participation: This study was conducted according to the guidelines laid down in the Declaration of Helsinki and all procedures involving human subjects/patients were approved by the Research Ethics Committee of the Coombe Women and Infants University Hospital. Written informed consent was obtained from all subjects/patients.

\section{References}

1. Institute of Medicine (1991) Nutrition during Lactation. Washington, DC: The National Academies Press.

2. American Academy of Pediatrics (2012) Breastfeeding and the use of human milk. Pediatrics 129, 827-841.

3. Tarrant RC, Younger KM, Sheridan-Pereira M et al. (2010) The prevalence and determinants of breast-feeding initiation and duration in a sample of women in Ireland. Public Health Nutr 13, 760-770.

4. Krause KM, Lovelady CA \& Østbye T (2011) Predictors of breastfeeding in overweight and obese women: data from Active Mothers Postpartum (AMP). Matern Child Health J 15, 367-375.

5. Kehler HL, Chaput KH \& Tough SC (2009) Risk factors for cessation of breastfeeding prior to six months postpartum among a community sample of women in Calgary, Alberta. Can J Public Health 100, 376-380.

6. Amir LH \& Donath SM (2008) Socioeconomic status and rates of breastfeeding in Australia: evidence from three recent national health surveys. Med J Aust 189, 254-256.

7. Clark M \& Ogden J (1999) The impact of pregnancy on eating behaviour and aspects of weight concern. Int J Obes Relat Metab Disord 23, 18-24.

8. Sadurkis A, Kabir N, Wager J et al. (1988) Energy metabolism, body composition and milk production in healthy Swedish women during lactation. Am J Clin Nutr 48, 44-49.

9. Symons Downs D \& Hausenblas HA (2004) Women's exercise beliefs and behaviors during their pregnancy and postpartum. J Midwifery Womens Health 49, 138-144.

10. Wiltheiss GA, Lovelady CA, West DG et al. (2013) Diet quality and weight change among overweight and obese postpartum women enrolled in a behavioural intervention program. J Acad Nutr Diet 113, 54-62.

11. Huseinovic E, Winkvist A, Bertz F et al. (2014) Changes in food choice during a successful weight loss trial in overweight and obese postpartum women. Obesity (Silver Spring) 22, 2517-2523.

12. Sharma AJ, Dee DL \& Harden SM (2014) Adherence to breastfeeding guidelines and maternal weight 6 years after delivery. Pediatrics 134, Suppl. 1, S42-S49.

13. Neville CE, McKinley MC, Holmes VA et al. (2014) The relationship between breastfeeding and postpartum weight change - a systematic review and critical evaluation. Int $J$ Obes (Lond) 38, 577-590.

14. Turner MJ (2011) The measurement of maternal obesity: can we do better? Clin Obes 1, 127-129.

15. Fattah C, Farah F, O'Toole F et al. (2009) Body mass index in women booking for antenatal care: comparison between self-reported and digital measurements. Eur $J$ Obstet Gynecol Reprod Biol 144, 32-34.

16. Central Statistics Office (2013) EU Survey on Income and Living Conditions (EU-SILC). 2011 and Revised 2010 Results. Dublin: Central Statistics Office.

17. European Commission Working Group (2003) Statistics on Income Poverty and Social Exclusion. Laeken Indicators Detailed Calculation Methodology. http://www.cso.ie/en/ media/csoie/eusilc/documents/Laeken,Indicators,-,calculation, algorithm.pdf (accessed June 2015).

18. Food and Agricultural Organization of the United Nations/ World Health Organization/United Nations University (2001) Human Energy Requirements. Report of a Joint FAO/ WHO/UNU Expert Consultation. Rome: FAO.

19. Food Safety Authority of Ireland (2011) Scientific Recommendations for Healthy Eating Guidelines in Ireland. Dublin: FSAI.

20. Health Service Executive (2013) Clinical Practice GuidelineNutrition for Pregnancy. Dublin: Institute of Obstetricians and 
Gynaecologists, Royal College of Physicians of Ireland and Directorate of Clinical Strategy and Programmes, HSE.

21. National Health and Medical Research Council (2013) Healthy Eating During Your Pregnancy - Advice on Eating for You and Your Baby (N55F). Canberra: Government of Australia.

22. Institute of Medicine, Panel on Dietary Reference Intakes for Macronutrients, Food and Nutrition Board (2002) Dietary Reference Intakes for Energy, Carbohydrate, Fiber, Fat, Fatty Acids, Cholesterol, Protein and Amino Acids. Washington, DC: National Academy Press.

23. Baker JL, Gamborg M, Heitmann BL et al. (2008) Breastfeeding reduces postpartum weight retention. Am J Clin Nutr 88, 1543-1551.

24. O'Higgins AC, Doolan A, Mullaney L et al. (2014) The relationship between gestational weight gain and fetal growth: time to take stock? J Perinat Med 42, 409-415.
25. Rockenbauer M, Olsen J, Czeizel AE et al. (2001) Recall bias in a case-control surveillance system on the use of medicine during pregnancy. Epidemiology 12, 461-466.

26. Schuit AJ, van Loon AJ, Tijhuis M et al. (2002) Clustering of lifestyle risk factors in a general adult population. Prev Med 35, 219-224.

27. Murimi M, Dodge CM, Pope J et al. (2010) Factors that influence breastfeeding decisions among special supplemental nutrition program for women, infants, and children participants from Central Louisiana. J Am Diet Assoc 110, 624-627.

28. Wosje KS \& Kalkwarf HJ (2004) Lactation, weaning, and calcium supplementation: effects on body composition in postpartum women. Am J Clin Nutr 80, 423-429.

29. Butte NF \& Hopkinson JM (1998) Body composition changes during lactation are highly variable among women. J Nutr 128, 2 Suppl., 381S-385S. 